\title{
CONTRIBUIÇÃO METODOLÓGICA PARA A ANÁLISE DA FRAGILIDADE EMERGENTE: ESTUDO DE CASO NO MUNICÍPIO DE COLOMBO/PR
}

\author{
Methodological contribution for the analysis of emergent \\ fragility: case study of the municipality of Colombo/PR
}

\author{
Luciano de ALMEIDA ${ }^{1}$ \\ Leonardo José Cordeiro SANTOS² \\ Guilherme Gandara MARTINS ${ }^{3}$
}

RESUMO

Este trabalho propõe uma adaptação da metodologia da Fragilidade Ambiental para a determinação da Fragilidade Emergente. Discute-se a necessidade de métodos de mensuração dos impactos causados pela agricultura que levem em conta diferentes práticas agrícolas e formas de manejo dos recursos naturais. Essa análise metodológica é realizada a partir de um estudo de caso no município de Colombo-PR, Região Metropolitana de Curitiba. Este município situa-se em uma área de mananciais e sobre um aquífero e pela presença da produção convencional e intensiva de hortaliças e de algumas culturas anuais. Foram elaboradas cartas de Fragilidade Ambiental (Potencial e Emergente) e avaliados os impactos da agricultura sobre a qualidade e disponibilidade dos recursos hídricos na área de estudo. Foram gerados novos parâmetros de diferenciação das práticas agrícolas e seus respectivos impactos ambientais. Os dados mostraram que, na medida em que são reconhecidas e analisadas com mais precisão as diferentes formas de uso agrícola do solo, os resultados em termos de fragilidade emergente também variam. No caso de Colombo, os dados mostram que a capacidade de proteção do solo é maior quando utilizada a metodologia proposta, mas reafirma que a agricultura praticada nas áreas de produção de hortaliças implica num elevado grau de vulnerabilidade do solo e, por decorrência, das águas. Conclui-se ainda que o procedimento metodológico apresentado é importante para que se rompa com uma visão equivocada que generaliza os impactos ambientais causados pela agricultura e se valorize iniciativas de uso de técnicas agrícolas de caráter mais conservacionista.

Palavras-chave: Fragilidade ambiental; Fragilidade emergente; Técnicas agrícolas.

\section{ABSTRACT}

This paper proposes an adaptation of the methodology of Environmental Fragility in order to detect Emergent Fragility. We discuss the needs for methods for measuring the impact of agriculture which take different agricultural practices and ways of using natural resources into account. This methodological analysis is carried out through a case study of the municipality of Colombo, Paraná, in Curitiba Metropolitan Region. This municipality is situated in an area of water springs and above an aquifer. It can be characterized by the presence of conventional and intensive vegetable production as well as the cultivation of several annual crops. We elaborated several charts on Environmental Fragility (Potential and Emergent) and evaluated the impact that agriculture has had on the quality and availability of water resources in the area we studied. We went on to generate new parameters for distinguishing agricultural practices and their respective environmental impacts. Data have shown that, to the extent that different forms of agricultural use of soil are recognized and analyzed with greater precision, prospects for emergent fragility also vary. In the case of Colombo, data show that the capacity for soil protection is greater when our proposed methodology is implemented, yet it restates the notion that agriculture that is practiced in areas where vegetables are grown implies high levels of soil vulnerability, also affecting water sources. Furthermore, we are led to conclude that the methodological procedures we propose are important so as to break an erroneous view that generalizes the environmental impacts that agriculture causes, and in order to place greater value on the use of more conservationist agricultural techniques.

Keywords: Environmental Fragility; Emergent Fragility; Agricultural techniques.

1 Doutor em Meio Ambiente e Desenvolvimento. Professor Adjunto da Universidade Federal do Paraná. E-mail: Iucianoalmeida@ufpr.br.

2 Doutor em Geografia Física. Professor Adjunto da Universidade Federal do Paraná. E-mail: santos@ufpr.br.

3 Engenheiro Agrônomo. 
ALMEIDA, L. de; SANTOS, L. J. C.; MARTINS, G. G. Contribuição metodológica para...

\section{INTRODUÇÃO}

A fragilidade do meio físico associada a intensos processos de degradação dos recursos naturais tem estimulado pressões e restrições à agricultura e, de modo geral, gerado fortes conflitos ambientais e sociais. A presença do aquífero Karst ${ }^{4}$ no município de Colombo-PR, e os procedimentos e perspectivas para se normatizar o uso do solo na área sob sua influência, reiteram a importância dos recursos hídricos desta região e a necessidade de se avaliar os impactos do padrão agrícola em curso.

Os elevados índices de precipitação, de cerca de $1500 \mathrm{~mm} / \mathrm{ano}$ (SANEPAR, 2001a), associados às características geomorfológicas e pedológicas, caracterizam um ambiente natural muito frágilem Colombo, tornando os solos bastante suscetíveis a processos erosivos (SANTOS; VITTE, 1998). Esta fragilidade adquire uma dimensão ainda maior em função de grande parte do município ser considerada como área de manancial, e estar situada sobre o aquífero Karst.

Quanto ao contexto socioespacial, destaca-se que a partir de 1995, com o início da exploração do aquífero Karst no município, tornou-se mais evidente a necessidade de se compatibilizar as diferentes formas de ocupação do solo com a exploração dos recursos hídricos. Este não é um fenômeno isolado. Ao contrário, ele se estende, num espaço mais imediato, a toda Região Metropolitana de Curitiba (RMC), tendo em vista a crescente necessidade de aumento da disponibilidade de água potável para a população urbana em crescimento. A importância que esse processo adquiriu nos últimos anos indica que, em breve, poderão ser implementadas medidas restritivas ao uso agrícola do solo na região.

Neste contexto, a exploração dos recursos hídricos superficiais e subterrâneos ${ }^{5}$, seja para abastecimento urbano ou para outros fins, entre eles a agricultura, tem sido objeto de intensos questionamentos.
Desta forma, julgou-se necessário elaborar uma cartografia da fragilidade ambiental, optando por uma metodologia que avaliasse os riscos de degradação ambiental prioritariamente em termos de processos erosivos, visto que a região de Colombo escolhida para o presente estudo caracteriza-se essencialmente pela atividade agrícola.

A erosão superficial representa o principal mecanismo de degradação dos recursos hídricos, sejam eles superficiais ou subterrâneos ${ }^{6}$. O escorrimento das águas da chuva implica não só no carreamento de solo que resulta no assoreamento dos rios e lagos, mas principalmente na condução de resíduos químicos e orgânicos para as águas superficiais e subterrâneas. De acordo com Merten (1994), o escorrimento das águas em solos agricultáveis provoca o transporte de nutrientes e agrotóxicos, principalmente herbicidas, para os cursos d'água. Em função disso, foi possível considerar o risco de erosão superficial como um indicador da fragilidade ambiental diante do uso agrícola.

Assim, este trabalho teve como objetivo elaborar cartas de Fragilidade Ambiental (Potencial e Emergente) do município de Colombo-PR e ao mesmo tempo, procurou: (i) propor uma adaptação da metodologia da Fragilidade Ambiental para a determinação da Fragilidade Emergente e (ii) avaliar os impactos da agricultura sobre a qualidade e disponibilidade dos recursos hídricos na área de estudo.

O termo fragilidade tem sido usado associado normalmente à qualidade dos espaços físicos, mais especificamente como "fragilidade do meio físico". Ele se refere à "suscetibilidade" e às causas de desequilíbrios do mesmo, relacionadas às ocupações e aos usos com frequência (SANTOS; VITTE, 1998). Pode-se associar ainda o termo fragilidade à noção de vulnerabilidade do meio frente a um dado processo de antropização, em particular quando se utiliza a expressão fragilidade emergente que relaciona a fragilidade potencial do meio ao uso e ocupação do solo.

4 Aquíferos são porções de rocha, sedimento ou solo, onde se consegue extrair volumes de água subterrânea em quantidades econômicas. Karst é um termo de sentido amplo, empregado para designar as áreas calcáreas ou dolomíticas, que possuem uma topografia característica, com a presença de dolinas (depressões fechadas) e cavernas, oriundas da dissolução de tais rochas. Estes locais caracterizam-se como um relevo bastante rebaixado, em relação ao contexto regional, com o lençol freático aflorante ou muito próximo da superfície (SANEPAR, 2001b).

5 Uma descrição detalhada dos recursos hidricos superficiais de do Aquífero Karst no município de Colombo pode ser encontrada em Almeida (2003)

6 Cabe ressalvar que o método proposto é limitado, sobretudo, quanto a sua capacidade de avaliar os riscos de contaminação das águas subterrâneas. Fritzons (1999), ao analisar o impacto ambiental da contaminação por nitrogênio na Bacia Hidroráfica kárstica de Fervida / Ribeirão das Onças, em Colombo, destaca que a vulnerabilidade diferencial dos solos à contaminação de águas subterrâneas varia de acordo com a pedologia, espessura, textura, estrutura, permeabilidade, capacidade de retenção de água, argila, percolação, profundidade, CTC, Ph, MO e composição do perfil do solo. Não foi possível, e tampouco era objetivo deste trabalho, desenvolver uma análise que considerasse todas estas variáveis, e assim, abrangesse toda a complexidade deste processo. 
ALMEIDA, L. de; SANTOS, L. J. C.; MARTINS, G. G. Contribuição metodológica para...

O mapeamento da fragilidade ambiental se fundamenta, em grande parte, nos trabalhos de Ross (1994; 1996), que tem se constituído numa referência para a análise da fragilidade dos ambientes naturais e antropizados. Segundo esse autor a caracterização integrada dos solos, relevo, rochas e minerais, águas, clima, flora e fauna, é o instrumento adequado para refletir a funcionalidade intrínseca entre os componentes físicos e bióticos, e inferir sobre a potencialidade dos recursos naturais frente à ocupação humana.

Esta perspectiva indica que a caracterização da fragilidade e do potencial dos ambientes antropizados resulta da análise integrada dos recursos naturais e do histórico e processos de uso e ocupação do ambiente, bem como dos projetos e perspectivas que os atores sociais locais têm para esse ambiente.

\section{PROCEDIMENTOS METODOLÓGICOS}

O Município de Colombo limita-se ao sul com os municípios de Curitiba, Pinhais e Quatro Barras, a oeste com Almirante Tamandaré, ao norte com Rio Branco do Sul e Bocaiúva do Sul e, a leste, com Campina Grande do Sul. (figura 1)

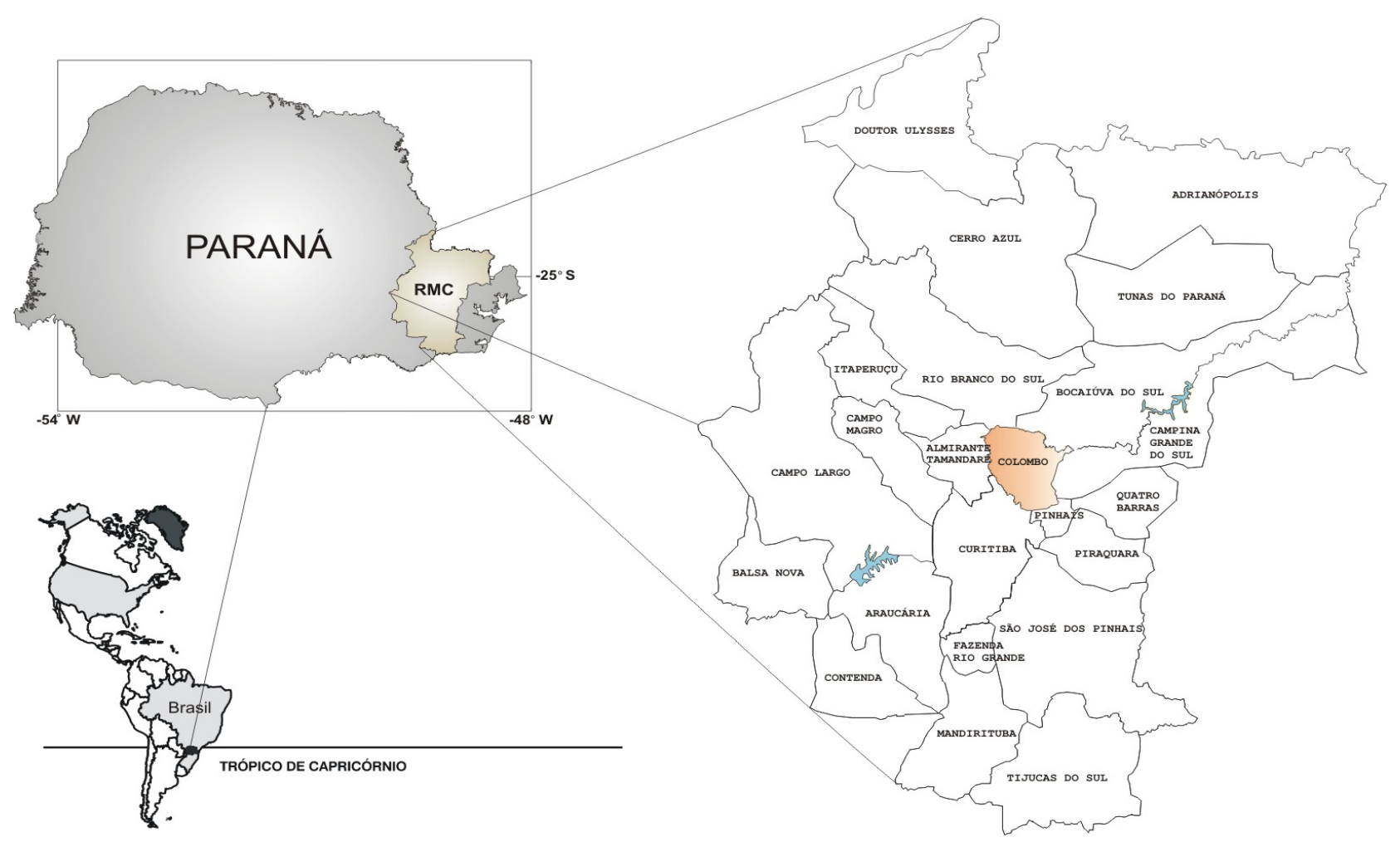

FIGURA 1 - LOCALIZAÇÃO DA RMC E DO MUNICÍPIO DE COLOMBO-PR

A análise da fragilidade ambiental foi realizada numa área deste município que concentra a produção de hortaliças, chamada aqui de Zona Agrícola. Esta área possui 11.389 hectares, corresponde a $57 \%$ do território de Colombo, concentra $92 \%$ da área agrícola deste município, e a quase totalidade da produção de hortaliças. Ela tem seus limites demarcados ao sul pela área urbana, a leste pelo divisor de águas da Bacia do Rio Palmital e a nordeste por divisores de águas de microbacias do Rio Capivari.
A delimitação desta área resultou de um levantamento do meio físico (declividade, hidrografia, solos), e do uso atual e histórico de ocupação, além da análise da paisagem. Foi elaborado o mapeamento com sobreposição de diferentes mapas na mesma escala de diferentes temas ${ }^{7}$ : a) declividade; b) solos; c) hidrografia; e) uso do solo.

O primeiro passo na construção da base carto-

7 Também foram considerados dados demográficos e a análise descritiva da paisagem. 
gráfica foi a elaboração de uma carta base, na escala 1:50.000, representando os limites do município de Colombo. A base cartográfica utilizada foi a folha topográfica $n^{\circ} 2842-2$ (IBGE, 1968). O mapa foi digitalizado e georreferenciado através do programa ArcView.

Uma vez delimitada a zona agrícola, os mapas de solos e declividade foram cruzados para gerar o mapa de fragilidade potencial ${ }^{8}$. A base de dados empregada na definição das classes de fragilidade potencial originou-se de mapas (carta de solos e planialtimétrica) e de dados de relatórios e boletins técnicos. Essa base foi preparada, através da técnica de digitalização em ambiente CAD (Computer Aid Designer), e submetida a tratamento computacional no Sistema de Informação Geográfica (SIG) ArcView.

A fragilidade potencial foi obtida por meio da análise integrada dos temas geomorfologia (mapa clinográfico/declividade) e pedologia (mapa de solos). Santos e Vitte (1998) argumentam a favor da equivalência entre os elementos do meio físico em sua influência na fragilidade potencial. A eventual hierarquização destes, com pesos diferenciados, implicaria em desconsiderar a influência que a atividade antrópica exerce na transformação destes elementos do meio em recursos, o que varia significativamente. Esta proposição é adequada ao caso deste estudo, sobretudo em função da análise da fragilidade limitar-se aos processos erosivos e considerar apenas os elementos pedologia e declividade.
Foram geradas duas matrizes intermediárias dos temas solos e declividade que permitiram o cruzamento posterior destes. Aqui, diferentemente de Santos e Vitte (1998) optou-se pela média entre as classes, e não pela classe mais alta, na elaboração da matriz para o cruzamento dos mapas temáticos, tal como mostra o Quadro 1. Considerou-se, conforme exposto anteriormente, que esta opção expressa melhor os riscos de degradação ou o grau de proteção dos solos, em especial, no que se refere à agricultura.

O passo seguinte após a conclusão do mapa de fragilidade potencial foi o confrontamento deste com o uso do solo. É neste ponto que este artigo se concentra. Comparam-se duas metodologias diferenciadas pela classificação do uso do solo. Uma delas, chamada aqui de "Metodologia "A"” corresponde a procedimentos mais frequentes ou consensuais em diversos estudos associados a análise da fragilidade emergente. Pode-se sintetizar essa metodologia na elaboração e utilização do mapa de uso do solo e de padrões prédeterminados para atribuição da capacidade de proteção das diferentes formas de uso. A segunda, aqui denominada de "Metodologia "B"' sugere alguns procedimentos diferenciados no sentido de detalhar o uso do solo, especificamente as atividades agrícolas, e a capacidade de proteção do solo destas.

QUADRO 1 - MATRIZ BÁSICA PARA O CRUZAMENTO DOS MAPAS TEMÁTICOS PELA MÉDIA E CÁLCULO DA FRAGILIDADE POTENCIAL FONTE: ALMEIDA (2003)

\begin{tabular}{|c|c|c|c|c|c|}
\hline $\begin{array}{l}\text { CLASSES DE } \\
\text { FRAGILIDADE }\end{array}$ & \multicolumn{5}{|c|}{ DECLIVIDADE } \\
\hline SOLOS & Muito Baixa 1 & Baixa 2 & Média 3 & Alta 4 & Muito Alta 5 \\
\hline Muito Baixa 1 & 1 & $(1.5) 1$ & 2 & $(2.5) 2$ & 3 \\
\hline Baixa 2 & $(1.5) 1$ & 2 & $(2.5) 2$ & 3 & $(3.5) 4$ \\
\hline Média 3 & 2 & $(2.5) 2$ & 3 & $(3.5) 4$ & 4 \\
\hline Alta 4 & $(2.5) 2$ & 3 & $(3.5) 4$ & 4 & $(4.5) 5$ \\
\hline Muito Alta 5 & 3 & $(3.5) 3$ & 4 & $(4.5) 5$ & 5 \\
\hline
\end{tabular}

NOTA: Os valores fracionários, entre parênteses, foram arredondados para o número inteiro imediatamente superior quando acima da média 3, e para o número inteiro imediatamente inferior quando abaixo da média 3. 
ALMEIDA, L. de; SANTOS, L. J. C.; MARTINS, G. G. Contribuição metodológica para...

\subsubsection{METODOLOGIA "A"}

Nesta metodologia, as informações sobre o uso do solo foram obtidas a partir de fotografias aéreas coloridas na escala 1:30.000, referente a junho de 2000, e mapa de uso e ocupação com relatório e padrões de ocupação (SUDERHSA, 2002). Este mapa não compreende a totalidade da área Zona Agrícola. Assim, com base nas fotografias aéreas, e utilizando-se os mesmos padrões de classificação do material Suderhsa (2002), procedeu-se à fotointerpretação de cerca de $30 \%$ da área, na escala 1:20.000.

A legenda do mapa de uso do solo constituiu-se dos seguintes padrões de ocupação (SUDERHSA, 2002):

Agricultura: são áreas destinadas a culturas temporárias ou do tipo perene, bem como solos preparados para o plantio;

- Vegetação Arbórea Plantada: são áreas plantadas com o objetivo de recomposição vegetal ou para a exploração comercial. Dentre as espécies consideradas nessas áreas estão a Bracatinga (Mimosa scabrella), o Pinheiro do Paraná e o Eucalipto;

- Vegetação Arbórea Natural: são áreas de vegetação arbórea natural em estágio avançado de regeneração.

- Vegetação Arbustiva Natural: são áreas de vegetação natural caracterizada por espécies que apresentam altura média de dois metros.

- Campo: são áreas que apresentam pouca ou nenhuma área construída, áreas rurais ocupadas por vegetação de baixo porte (vegetação rasteira), destinadas ou não à pecuária.

- Mineração / Solo Exposto: agrega as áreas de extração de lavras de calcáreo e pedreiras para extração de brita. Inclui ainda áreas abertas, desprovidas de cobertura vegetal que ocorrem em ambiente rural e/ou urbano.

- Água / Banhado: os elementos de hidrografia que compõem esta classe são rios perenes e intermitentes, lagos, lagoas, açudes, represas, valas e drenos, canais, canais de irrigação, cavas e tanques. Estão aqui agregados também os terrenos alagados que apresentam ou não vegetação herbácea.

- Área Urbana: foram agregadas aqui diversas classes do material de origem (SUDERHSA, 2002) tais como: área urbana com alto, médio e baixo índice de impermeabilização do solo, áreas industriais, loteamentos, armazéns ou silos. São áreas ocupadas por construções para fins residenciais, comerciais ou industriais, sendo estas esparsas ou densas, com ruas com ou sem pavimentação.

- Vila: são áreas de ocupação humana descontínuas ou isoladas das manchas de urbanização, ocupadas por casas de um pavimento, terrenos vazios, bem como postos de gasolina, sítios e fazendas, passíveis de serem mapeados na escala de trabalho.

Nessa metodologia "A" fez-se a adequação dos padrões de ocupação às classes de capacidade de proteção propostos por Ross (1994). Este autor, com base em inúmeros trabalhos, propõe uma hierarquia de graus de proteção aos solos pela cobertura vegetal, em ordem decrescente da capacidade de proteção, definindo-se assim algumas categorias como segue:

- Muito alta: áreas de florestas/matas naturais, florestas cultivadas com biodiversidade;

- Alta: formações arbustivas naturais com estrato herbáceo denso, formações arbustivas densas (mata secundária, capoeira densa), mata homogênea de Pinus densa, e pastagens cultivadas com baixo pisoteio de gado.

- Média: Cultivos de ciclo longo em curvas de nível como café, laranja com forrageiras entre ruas, pastagens com baixo pisoteio, silvicultura de eucaliptos com sub-bosque de nativas.

- Baixa: Culturas de ciclo longo de baixa densidade com solo exposto entre ruas (laranja, café), culturas de ciclo curto (arroz, soja, feijão, milho) com cultivo em curvas de nível.

- Muito Baixa: Áreas desmatadas e queimadas recentemente, solo exposto por arado / gradeação, solo exposto ao longo de caminhos e estradas, terraplanagens, culturas de ciclo curto sem práticas conservacionistas.

Para este estudo, diante das classes de uso do solo adotadas da Suderhsa (2002), fez-se uma adaptação das categorias a partir dos padrões de uso do solo do mapeamento e do conhecimento da paisagem, gerando as classes de proteção dos solos tal como se apresenta na tabela 1. Procurou-se manter os critérios centrais da classificação de Ross (1994), ainda que se tenha identificado fortes restrições desse enquadramento, como se discutirá adiante. 
ALMEIDA, L. de; SANTOS, L. J. C.; MARTINS, G. G. Contribuição metodológica para...

TABELA 1 - GRAU DE PROTEÇÃO DOS PADRÕES DE OCUPAÇÃO NA ZONA AGRÍCOLA - COLOMBO

\begin{tabular}{|c|c|}
\hline GRAUS DE PROTEÇÃO & PADRÕES DE OCUPAÇÃO \\
\hline 1 - Muito Alta & Vegetação Arbórea Natural \\
\hline $2-$ Alta & Vegetação Arbórea Plantada \\
\hline 3 - Média & Campo, Vegetação Arbustiva Natural \\
\hline 4 - Baixa & Agricultura \\
\hline \multirow[t]{2}{*}{5 - Muito Baixa } & Mineração/Solo Exposto \\
\hline & *Área Urbana / Vila / Água e Banhado \\
\hline
\end{tabular}

FONTE: ALMEIDA (2003)

NOTA: *Os usos "Área Urbana”, "Vila”, "Água” e "Banhado”, não foram considerados na atribuição de graus de proteção.

As categorias "Vegetação Arbórea Natural" e "Vegetação Arbórea Plantada", ainda que enquadradas como graus de proteção distintos, tendem a aproximarse na realidade. $O$ trabalho de campo sugere que os remanescentes de floresta primária são inferiores aos valores identificados a partir do tratamento das fotos aéreas. É possível afirmar ainda que as categorias Floresta Natural e Floresta Plantada diferenciam predominantemente distintos níveis de uma floresta secundária onde predomina, mais ou menos intensamente, a bracatinga.

Destaca-se que, na classificação de Ross (1994) a agricultura é distribuída nas classes "média", "baixa" e "muito baixa" em termos de proteção do solo, em função dos sistemas de cultivo, do ciclo das culturas, práticas de conservação e padrões tecnológicos. Esse procedimento é inadequado para a agricultura de Colombo, quando analisada a produção de culturas de ciclo curto, e exige adaptações. Neste caso, toda a agricultura foi enquadrada na classe de baixa proteção. Fez-se isso por diferentes razões. No mapeamento não foi possível diferenciar culturas de ciclo longo e curto, não permitindo que esse critério fosse utilizado no enquadramento nas classes de proteção. Isso fez com que a classe de "média" proteção, tal como delimitada por Ross (1994), não pudesse ser diferenciada. Apesar desta adequação mostrar uma limitação do enquadramento proposto por este autor, no caso em estudo, esta restrição não trouxe implicações para os resultados. Isto se deve ao fato de que as culturas de ciclo longo são ocasionais e restritas a pequenos pomares de uva, numa região onde predomina a produção de culturas anuais e hortaliças.

Por outro lado, não seria razoável considerar a agricultura na classe de "Muito Baixo" grau de proteção. As escalas de produção e a diversidade de culturas são muito variadas, assim como ocorrem distintas formas de manejo do solo proporcionando níveis de proteção diferenciados. Além disso, enquadrar a agricultura como "muito baixa proteção" implicaria em compará-la à mineração como forma de ocupação do solo. A mineração tem uma presença significativa em Colombo, com extensas áreas degradadas por essa atividade. O impacto dessa prática é de tamanha expressão que seria um equívoco nivelá-la com a agricultura do município em termos de nível de proteção do solo.

Assim, destaca-se novamente que a agricultura foi classificada como de "baixa" capacidade de proteção do solo, para efeito de geração de um Mapa de Fragilidade Emergente, indicador do grau de vulnerabilidade dos recursos naturais diante da cobertura do solo.

A partir desse enquadramento procedeu-se análise integrada da fragilidade potencial do meio natural e do uso do solo para gerar o mapa de fragilidade emergente. Considerou-se que a fragilidade ambiental depende diretamente da fragilidade potencial do meio natural e igualmente do potencial da ação antrópica em impactá-lo. Assim, também nesse caso, optou-se por uma matriz que considerasse a média entre estes dois elementos, como mostra o Quadro 2.

$\mathrm{Na}$ Metodologia "A" foram utilizados o mapa de uso do solo, e a grade de enquadramento das diferentes formas de uso e ocupação em classes de fragilidade emergente. Ainda que estes produtos sejam ilustrativos e importantes na escala da Zona Agrícola, considera-se que da forma como foram constituídos guardam fortes de imprecisões uma vez que não diferenciam os padrões agrícolas existentes. Ou seja, nessa metodologia há uma padronização das agriculturas, cujos impactos passam a variar exclusivamente em função de diferenças no meio físico. 
ALMEIDA, L. de; SANTOS, L. J. C.; MARTINS, G. G. Contribuição metodológica para...

QUADRO 2 - MATRIZ BÁSICA PARA O CRUZAMENTO DOS MAPAS TEMÁTICOS PELA MÉDIA E CÁLCULO DA FRAGILIDADE EMERGENTE

\begin{tabular}{|c|c|c|c|c|c|}
\hline \multirow{2}{*}{\begin{tabular}{|c|c|} 
GLASSES DE FRAGILIDADE \\
FRAGILIDADE POTENCIAL
\end{tabular}} & Muito Baixa 1 & Baixa 2 & Média 3 & Alta 4 & Muito Alta 5 \\
\hline Muito Baixa - 1 & 1 & $(1.5) 2$ & 2 & $(2.5) 2$ & 3 \\
\hline Baixa -2 & $(1.5) 1$ & 2 & $(2.5) 2$ & 3 & $(3.5) 4$ \\
\hline Média -3 & 2 & $(2.5) 2$ & 3 & $(3.5) 4$ & 4 \\
\hline Alta -4 & $(2.5) 2$ & 3 & $(3.5) 4$ & $(4.5) 5$ \\
\hline Muito Alta -5 & 3 & $(3.5) 4$ & 4 & (4.5) 5 & 5 \\
\hline
\end{tabular}

FONTE: ALMEIDA (2003)

NOTA: Os valores fracionários foram arredondados para o número inteiro imediatamente superior quando acima da média 3, e para o número inteiro imediatamente inferior quando abaixo da média

As restrições da hierarquia de graus de proteção dos solos pela cobertura vegetal proposta por Ross (1994) fizeram com que toda a agricultura de Colombo fosse classificada como de Baixa Capacidade de Proteção do Solo. Isso sugere que a produção de culturas temporárias, principalmente hortaliças, causa sempre o mesmo impacto, independentemente das práticas agrícolas e do manejo dos recursos naturais. Dito de outra forma, a atribuição de um único nível de proteção do solo para diferentes formas de praticar a agricultura é arbitrária e tende a escamotear variações importantes na capacidade de proteção do solo.

As restrições da Metodologia "A" também têm sido atribuídas à utilização da metodologia de Ross (1994) para avaliar a efetiva vulnerabilidade dos recursos naturais de um dado espaço diante das formas de ocupação. Alega-se que as classes de proteção do solo estabelecidas e o enquadramento, sobretudo da agricultura, não reflete a diversidade de formas de manejo agrícola do solo, e, portanto, são restritas diante das variadas formas de agricultura, de manejo dos recursos naturais, cujos impactos ambientais também são diversos. Quanto a estas restrições o trabalho de Floriani (2003) aponta algumas alternativas.

O mapa de fragilidade emergente gerado a partir dessa metodologia será apresentado posteriormente.

\subsubsection{METODOLOGIA “B”}

No caso deste artigo, dado o objetivo de evidenciar o real impacto da agricultura em curso, sobretudo da produção de hortaliças, para a conservação dos recursos naturais, fez-se necessário buscar uma alternativa metodológica em caráter experimental que procura aperfeiçoar a análise do duplo condicionamento das características do meio físico e das práticas agrícolas em termos de impacto ambiental ${ }^{9}$.

A partir destas considerações, o trabalho procurou articular o exercício cartográfico da fragilidade potencial com o levantamento de campo nas propriedades agrícolas, de modo a gerar um indicador da fragilidade emergente, em termos de erosão, em cada unidade estudada. Ou seja, se na metodologia "A" levou-se em consideração a área total da agricultura para os cruzamentos, na metodologia "B" utilizou-se somente as áreas de produção de hortaliças das propriedades ${ }^{10}$.

Diante destas restrições, e da disponibilidade dos mapas de solos e declividade, optou-se por avaliar os processos erosivos a partir da associação entre dados cartográficos sobre as características do meio físico e indicadores do manejo dos solos nas unidades. A partir do georeferenciamento de cada propriedade, projetou-se no mapa de fragilidade potencial o conjunto das unidades analisadas, o que permitiu o enquadramento das áreas de cultivo de cada propriedade numa determinada classe

9 A partir dos mesmos pressupostos, ainda que utilizando metodologias distintas, é ilustrativo o trabalho de Oliveira (2000). Esta autora desenvolve um estudo de caso no município de Leme -SP, analisando os impactos ambientais a partir de parâmetros técnicoagronômicos referentes às práticas agrícolas realizadas pelos produtores, assim como, baseado nas condições de relevo e nas características dos solos. 
de fragilidade potencial. Esse dado foi então correlacionado com as práticas de conservação e o manejo do solo nas respectivas áreas de produção, gerando um indicador da capacidade de proteção do solo em cada unidade, ou, um indicador da fragilidade emergente nas unidades. Esse índice reflete o impacto ambiental da agricultura, especificamente da produção de hortaliças, em termos de riscos de erosão e contaminação de recursos hídricos.

É importante reforçar que a atividade agrícola predominante em Colombo, e aqui analisada é a produção de hortaliças a partir de técnicas convencionais de produção. Estas técnicas são o revolvimento intenso do solo a partir do uso de máquinas e implementos agrícolas para a produção de culturas de ciclo curto. O detalhamento das diferenciações na implementação e manejo destas culturas constitui-se no procedimento diferenciador desta metodologia.

Cabe destacar ainda que o índice gerado na Metodologia "B" diz respeito exclusivamente à agricultura / produção de hortaliças, e não considera outras formas de uso e ocupação do solo nas unidades de exploração. Ou seja, ele é capaz de indicar o impacto da olericultura na área utilizada e não do conjunto das formas de uso e ocupação, tais como a existência ou não de cobertura florestal, entre outros. Em síntese, ele mostra qual o potencial de conservação do solo decorrente das práticas e do manejo existente, ou, de outra forma, o impacto da agricultura em termos de processos erosivos.
Nesse sentido, foram utilizadas as variáveis a) Práticas de Conservação e b) Manejo e implementos de preparo dos solos, na elaboração deste índice de conservação do solo. Inicialmente cada variável gerou uma nota entre 0 e 10.

A variável Práticas de Conservação foi composta a partir da ocorrência ou não de práticas orientadas para a conservação dos solos. A nota final resultou da somatória de práticas de conservação existentes na unidade, até a nota máxima de 10 . As práticas consideradas constituem recomendações técnicas consensuais ou são práticas utilizadas pelos agricultores que, embora sua capacidade de conservação dos solos seja paleativa ou restritiva, são citadas espontaneamente pelos agricultores como estratégias de conservação dos solos. Estas últimas práticas foram selecionadas a partir de um conjunto de técnicas citadas pelos agricultores, submetidas à análise de especialistas na área. Foram pontuadas as seguintes práticas: plantio em nível; adubação verde; cobertura morta; pousio; rotação de culturas; adubos orgânicos; curva de nível; consorciação de culturas; incorporação de restos culturais ou mato; terraceamento; e uso de sulcador ou arado com tração animal em nível.

A variável Manejo e Implementos de Preparo do Solo foi composta por três indicadores: implementos de preparo do solo; número de preparos do solo e; sentido do preparo do solo. Resulta também numa escala de 0 a 10, do potencial de conservação do solo, cuja composição é descrita no tabela 2.

TABELA 2 - CAPACIDADE DE PROTEÇÃO DO SOLO EM FUNÇÃO DO MANEJO

\begin{tabular}{|c|c|}
\hline MANEJO E IMPLEMENTOS - INDICADORES & NOTA \\
\hline \multicolumn{2}{|l|}{ Implementos de preparo do solo - Sem uso de } \\
\hline Enxada Rotativa & 2 \\
\hline Grade & 1 \\
\hline Arado & 1 \\
\hline Carpideira & 1 \\
\hline (1) & 0.5 \\
\hline 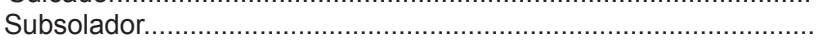 & 0.5 \\
\hline \multicolumn{2}{|l|}{ Sem preparo $\quad$ úmeros de preparos do solo (1) } \\
\hline 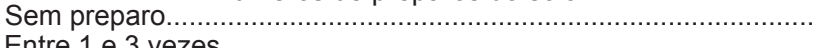 & 2 \\
\hline & 1 \\
\hline 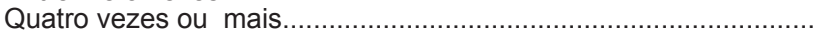 & 0 \\
\hline \multicolumn{2}{|l|}{ Sentido do preparo do solo } \\
\hline Em nível.............. & 2 \\
\hline "Atravessado"(2) .................. & 1 \\
\hline 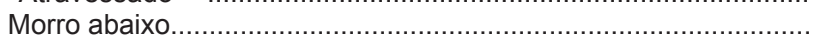 & 0 \\
\hline Total & 0 a 10 \\
\hline
\end{tabular}

FONTE: ALMEIDA (2003)

NOTAS:(1) Número de preparos para o plantio, numa mesma área, no período de um ano.

(2) Refere-se ao preparo do solo, prioritariamente em linha reta, transversal à principal vertente. Ainda que tal prática seja positiva quando comparada com o plantio morro abaixo, ela não pode ser comparada com o plantio em nível, uma vez que mudanças de vertente podem restringir ou até mesmo inverter a capacidade de evitar o escorrimento superficial.

10 Foram selecionadas 39 propriedades produtoras de hortaliças, representativas de um conjunto de 310. Os parâmetros da seleção desta amostra podem ser encontrados em Almeida (2003). 
ALMEIDA, L. de; SANTOS, L. J. C.; MARTINS, G. G. Contribuição metodológica para...

A média das notas das duas variáveis mostra qual o potencial de conservação do solo, onde 10 corresponde à maior capacidade de proteção do solo e 0 a menor.
Estas médias foram ponderadas em graus de proteção dos solos, para que fossem utilizadas na geração da fragilidade emergente, conforme o quadro 3 .

QUADRO 3 - CAPACIDADE DE PROTEÇÃO DO SOLO PARA VALORES DO ÍNDICE DE CONSERVAÇÃO DO SOLO

\begin{tabular}{|cc|}
\hline CONSERVAÇÃO DO SOLO & CAPACIDADE DE PROTEÇÃO DO SOLO \\
\hline $\mathrm{n} *<\mathrm{ou}=\mathrm{a} 2$ & 1 - Muito Baixa \\
$2<\mathrm{n}<\mathrm{ou}=\mathrm{a} 4$ & 2 - Baixa \\
$4<\mathrm{n}<\mathrm{ou}=6$ & 3 - Média \\
$6<\mathrm{n}<\mathrm{ou}=\mathrm{a} 8$ & 4 - Alta \\
$8<\mathrm{n}<\mathrm{ou}=\mathrm{a} 10$ & 5 - Muito Alta \\
\hline
\end{tabular}

FONTE: ALMEIDA (2003)

NOTA: $n^{*}$ corresponde ao valor do índice de conservação do solo.

\section{RESULTADOS E DISCUSSÃO}

\subsection{FRAGILIDADE POTENCIAL}

O mapa de fragilidade potencial (mapa 1) gerado serviu de base para as duas metodologias analisadas.

A tabela 3 apresenta os valores absolutos e relativos das áreas de diferentes classes de fragilidade potencial. Pode-se observar que $60 \%$ da zona agrícola apresenta uma fragilidade potencial alta e muito alta. Se for considerada a classe média nesse conjunto, ter-se-á quase $75 \%$ das áreas com riscos potencial de processos erosivos. Isso indica que a área em estudo pode apresentar grandes problemas quanto à erosão, ao assoreamento dos córregos e contaminação das águas. Pode-se concluir ainda, que o resultado obtido na fragilidade muito alta está relacionado sobretudo com solos, e que na classe alta, a declividade apresenta uma pequena prioridade de determinação.

A parcela correspondente às classes de fragilidade baixa e muito baixa indicam serem áreas próprias para o uso agrícola, principalmente por estarem situadas no intervalo de classe de declividade abaixo de $8 \%$. Porém, apresentam restrições quanto ao uso de adubos e agrotóxicos devido à proximidade do lençol freático e da água dos rios. A classe de fragilidade média indica a necessidade de cuidados especiais na utilização dessas áreas para fins agrícolas, principalmente naqueles locais de relevo movimentado e próximo das águas dos rios e córregos.

TABELA 3 - FRAGILIDADE POTENCIAL, DECLIVIDADE E PEDOLOGIA PARAA ZONAAGRÍCOLA: VALORES ABSOLUTOS E RELATIVOS DAS ÁREAS SEGUNDO AS CLASSES DE FRAGILIDADE

\begin{tabular}{|c|c|c|c|c|c|c|}
\hline \multirow{2}{*}{$\begin{array}{l}\text { CLASSES DE } \\
\text { FRAGILIDADE }\end{array}$} & \multicolumn{6}{|c|}{ ÁREA EM HECTARES E \% } \\
\hline & $\begin{array}{l}\text { DECLIVIDADE } \\
\text { (ha) }\end{array}$ & $\%$ & $\begin{array}{l}\text { PEDOLOGIA } \\
\text { (ha) }\end{array}$ & $\%$ & $\begin{array}{l}\text { F RA G I LID A D E } \\
\text { POTENCIAL (ha) }\end{array}$ & $\%$ \\
\hline 1 - Muito Baixa & 1887,84 & 17,84 & 1470,68 & 13,89 & 648,34 & 6,13 \\
\hline 2 - Baixa & 929,96 & 8,79 & 280,20 & 2,65 & 2034,60 & 19,23 \\
\hline 3 - Média & 3750,88 & 35,45 & 1627,81 & 15,37 & 1545,06 & 14,60 \\
\hline $4-$ Alta & 3079,40 & 29,10 & 2161,81 & 20,42 & 3629,94 & 34,30 \\
\hline 5 - Muito Alta & 933,92 & 8,83 & 5047,76 & 47,67 & 2724,07 & 25,74 \\
\hline Total & 10582,00 & 100,00 & 10588,25 & 100,00 & 10582,00 & 100,00 \\
\hline
\end{tabular}

FONTE: ALMEIDA (2003) 
ALMEIDA, L. de; SANTOS, L. J. C.; MARTINS, G. G. Contribuição metodológica para...

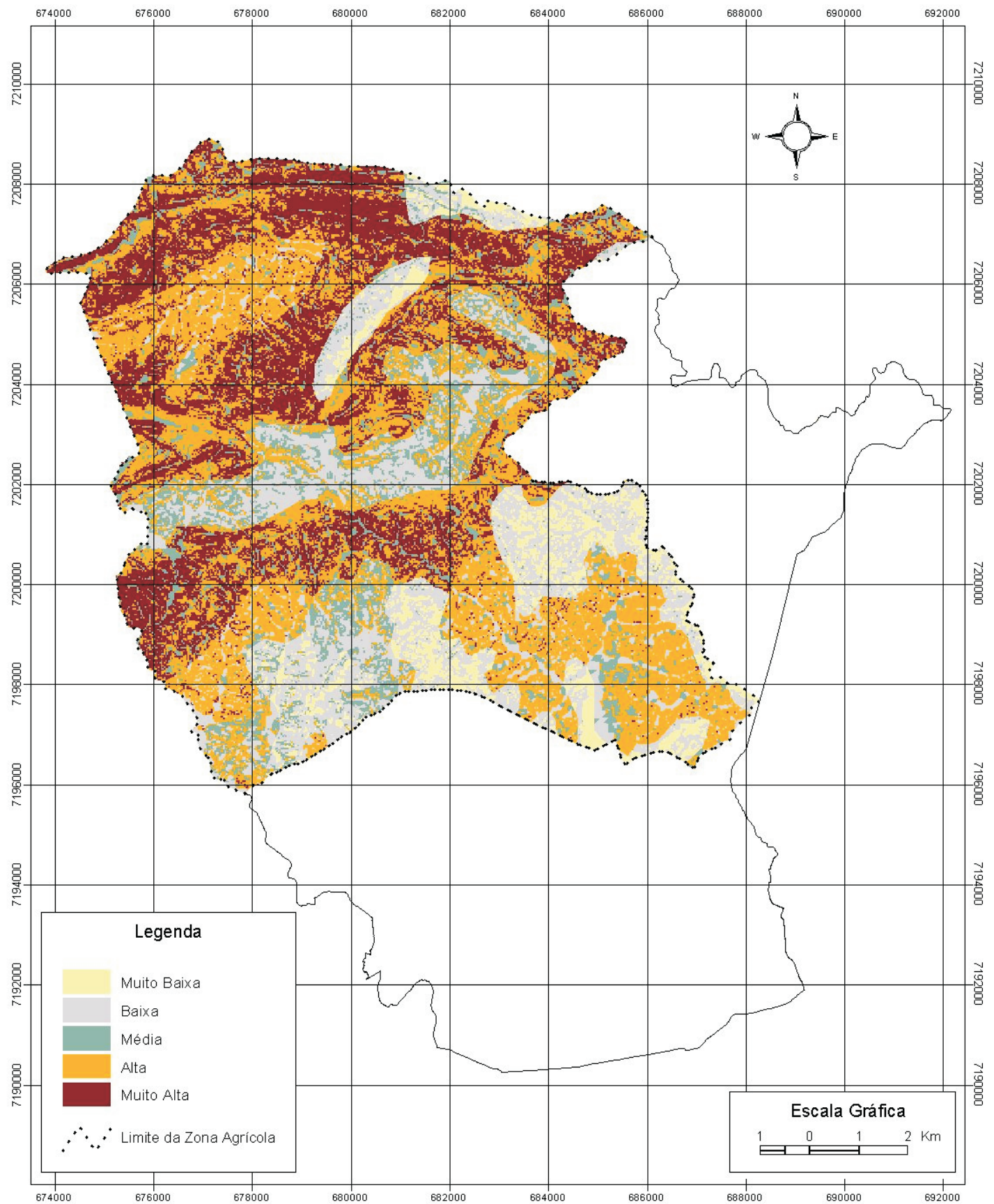

MAPA 1 - FRAGILIDADE POTENCIAL NA ZONA AGRÍCOLA DE COLOMBO 
ALMEIDA, L. de; SANTOS, L. J. C.; MARTINS, G. G. Contribuição metodológica para...

\subsection{FRAGILIDADE EMERGENTE METODOLOGIA "A"}

Apresenta-se inicialmente os resultados em termos de fragilidade emergente a partir do uso da Metodologia " $A$ ", conforme descrita anteriormente. O confrontamento do mapa de fragilidade potencial com o mapa de uso e ocupação do solo resultou na fragilidade emergente o que permitiu avaliar os riscos reais na área em estudo.

Quanto ao uso do solo, a tabela 4 mostra que a agricultura, com 1994 hectares, ocupa apenas 17,9\% da área da Zona Agrícola. Ao mesmo tempo destaca-se o fato de $53,8 \%$ do território estar ocupado por vegetação arbórea, cujo grau de proteção do solo é considerado alto ou muito alto. Agregando e estes dados as áreas de vegetação arbustiva e pastagens que, predominantemente tem muito baixa ou nenhuma ocupação na área estudada, tem-se $74,2 \%$ da Zona Agrícola com médio ou elevado grau de proteção do solo. Nesse sentido, a Zona Agrícola, onde se concentra a produção de hortaliças de Colombo, possui um grau muito elevado de cobertura vegetal e proteção do solo.

TABELA 4 - VALORES ABSOLUTOS E RELATIVOS DOS DIFERENTES PADRÕES DE OCUPAÇÃO NA ZONA AGRÍCOLA

\begin{tabular}{|c|c|c|c|}
\hline \multirow[t]{2}{*}{ GRAUS DE PROTEÇÃO } & \multirow{2}{*}{ TIPOS DE COBERTURA VEGETAL } & \multicolumn{2}{|c|}{ ZONAAGRÍCOLA } \\
\hline & & ÁREA(HA) & $\%$ \\
\hline 1 - Muito Alta & Vegetação Arbórea Natural & 3882,84 & 34,1 \\
\hline $2-$ Alta & Vegetação Arbórea Plantada & 2245,61 & 19,7 \\
\hline 3 - Média & Campo, Vegetação Arbustiva Natural & 2324,14 & 20,4 \\
\hline 4 - Baixa & Agricultura & 1994,15 & 17,9 \\
\hline \multirow[t]{2}{*}{5 - Muito Baixa } & Mineração/Solo Exposto & 135,26 & 1,2 \\
\hline & *Área Urbana / Vila / Água e Banhado & 807,55 & 6,7 \\
\hline Total & & 11389,5 & 100 \\
\hline
\end{tabular}

FONTE: Almeida (2003)

O cruzamento dos mapas temáticos fragilidade potencial e uso e ocupação do solo, conforme matriz apresentada anteriormente, permitiu a elaboração do mapa de fragilidade emergente (mapa 2).
O conjunto dos dados por classes de fragilidade relativos à fragilidade potencial, uso do solo e fragilidade emergente constam na tabela 5.

TABELA 5 - FRAGILIDADE EMERGENTE, FRAGILIDADE POTENCIAL E USO DO SOLO NA ZONA AGRÍCOLA: VALORES ABSOLUTOS E PERCENTUAIS DAS ÁREAS SEGUNDO AS CLASSES DE FRAGILIDADE

\begin{tabular}{|c|c|c|c|c|c|c|}
\hline \multirow{3}{*}{$\begin{array}{l}\text { CLASSES DE } \\
\text { FRAGILIDADE }\end{array}$} & \multicolumn{6}{|c|}{ ÁREA EM HECTARES E \% } \\
\hline & FRAGILIDADE & $\%$ & USO DO SOLO & $\%$ & FRAGILIDADE & $\%$ \\
\hline & POTENCIAL & & & & EMERGENTE & \\
\hline 1 - Muito Baixa & 648,34 & 6,13 & 3882,83 & 36,69 & 1035,42 & 9,79 \\
\hline 2 - Baixa & 2034,60 & 19,23 & 2245,61 & 21,22 & 3304,16 & 31,22 \\
\hline 3 - Média & 1545,06 & 14,60 & 2324,14 & 21,96 & 2656,59 & 25,11 \\
\hline $4-$ Alta & 3629,94 & 34,30 & 1994,15 & 18,84 & 3123,27 & 29,52 \\
\hline 5 - Muito Alta & 2724,07 & 25,74 & 135,26 & 1,28 & 462,57 & 4,37 \\
\hline Total & 10582,00 & 100,00 & 10582,00 & 100,00 & 10582,00 & 100,00 \\
\hline
\end{tabular}

FONTE: Almeida (2003) 
Os dados mostram que $66 \%$ da Zona Agrícola está situada entre as classes de fragilidade emergente muito baixa, baixa e média, resultante da ocupação atual do solo por atividades de baixo risco ambiental, ou seja, por uma vegetação com elevada capacidade de proteção do solo. Entretanto, isto não minimiza o fato de quase $34 \%$ da área em estudo ser classificada como de alta ou muito alta fragilidade emergente. Tal condição deriva sobretudo da elevada fragilidade natural destas áreas, associada à presença da agricultura, considerada como de baixa capacidade de proteção do solo.

Estes dados também permitem estimar o impacto ambiental do uso agrícola, a partir da localização desta em áreas mais ou menos frágeis. Nesse sentido, ainda que a agricultura ocupe limitados $18 \%$ da Zona Agrícola, observa-se que quase $55 \%$ da atividade agrícola localiza-se nas áreas de alta ou muito alta fragilidade potencial. Somando-se a estes dados as áreas de média fragilidade, ter-se-á que $73 \%$ da agricultura da Zona Agrícola se realiza em áreas de risco potencial.

\subsection{FRAGILIDADE EMERGENTE / METODOLOGIA "B"}

A metodologia "B" se diferencia por detalhar a capacidade de proteção do solo nas propriedades a partir das distintas práticas agrícolas e formas de manejo dos solos. Isso foi realizado nas áreas de produção de cada propriedade. ${ }^{11}$ Como foi exposto anteriormente, a partir do georeferenciamento de cada unidade, projetou-se no mapa de fragilidade potencial o conjunto das propriedades permitindo o enquadramento das áreas de cultivo de cada uma destas numa determinada classe de fragilidade potencial. Esse dado foi então correlacionado com as práticas de conservação e o manejo do solo usadas pelo respectivo agricultor, gerando um indicador da capacidade de proteção do solo em cada propriedade. Procedeu-se o somatório do conjunto destas áreas por capacidade de proteção para que se pudesse comparar com os dados de fragilidade potencial e emergente obtido a partir da análise de toda a Zona Agrícola (Metodologia "A") ${ }^{12}$. A tabela 6 mostra que $47,9 \%$ das áreas de hortaliças nas propriedades se enquadram como baixa ou muito baixa capacidade de proteção, enquanto que $52,2 \%$ situam-se em média ou alta capacidade de proteção do solo.

Observa-se que se confirma o fato da agricultura / produção de hortaliças praticada ser impactante ao meio ambiente. Contudo, os dados também mostram que a capacidade efetiva de proteção do solo da agricultura praticada em Colombo é maior do que a pré-estabelecida anteriormente na geração do mapa de fragilidade emergente, a partir da Metodologia "A", onde $100 \%$ da agricultura foi considerada como de baixa capacidade de proteção.

TABELA 6 - CLASSIFICAÇÃO DA AGRICULTURA SEGUNDO AS CLASSES DE CAPACIDADE DE PROTEÇÃO DO SOLO A PARTIR DA METODOLOGIA “A” (ZONAAGRÍCOLA) E DO INDICADOR DAS UNIDADES DE PRODUÇÃO CONVENCIONAL

\begin{tabular}{c|c|c}
\hline CAPACIDADE DE PROTEÇÃO & $\begin{array}{c}\text { NA ZONA AGRÍCOLA } \\
\text { \% (da área agrícola) }\end{array}$ & $\begin{array}{c}\text { NAS UNIDADES DE PRODUÇÃO } \\
\% \text { (da área de hortaliças) }\end{array}$ \\
\hline Muito Baixa & 0 & 0,3 \\
Baixa & 100 & 47,6 \\
Média & 0 & 43,5 \\
Alta & 0 & 8,7 \\
Muito Alta & 0 & 0 \\
Total & 100 & 100 \\
\hline
\end{tabular}

FONTE: Almeida (2003)

11 O somatório das áreas de produção de hortaliças do conjunto das propriedades analisadas corresponde a 171,6 hectares.

12 O principal objetivo deste índice é analisar os efetivos riscos ambientais da agricultura convencional praticada em Colombo. Nesse sentido foram considerados 39 agricultores convencionais cujo padrão técnico de produção é utilizado por $90 \%$ dos olericultores de Colombo. 
ALMEIDA, L. de; SANTOS, L. J. C.; MARTINS, G. G. Contribuição metodológica para...

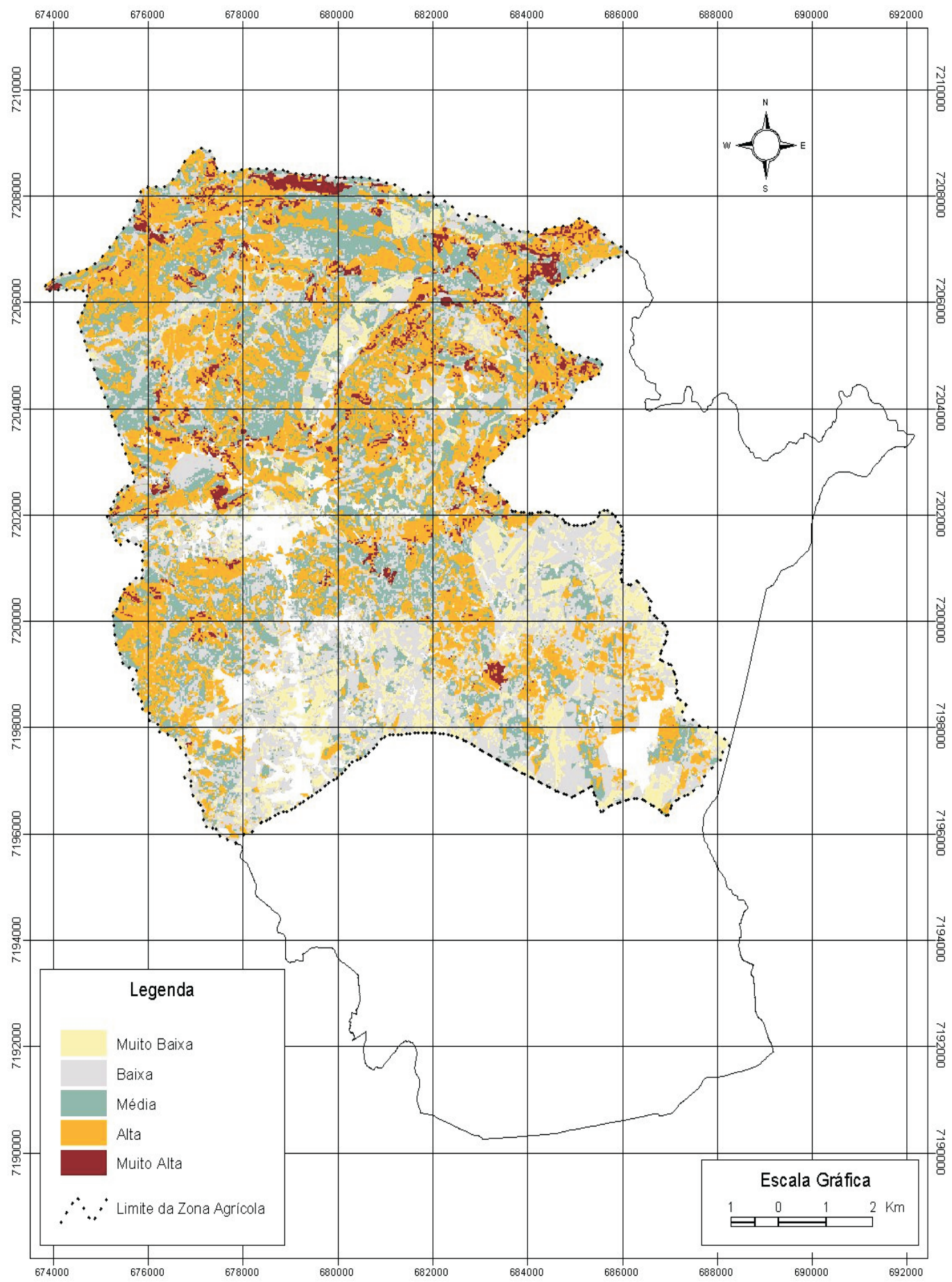

MAPA 2 - FRAGILIDADE EMERGENTE NA ZONA AGRÍCOLA 
ALMEIDA, L. de; SANTOS, L. J. C.; MARTINS, G. G. Contribuição metodológica para...

A partir dessa reclassificação foi reelaborada a fragilidade emergente, especificamente para a agricultura praticada nas unidades em estudo, considerando os valores pontuais da capacidade de proteção dos solos.

Os valores de capacidade de proteção dos solos foram convertidos em classes de fragilidade permitindo o cruzamento com a fragilidade potencial em cada propriedade, seguindo os mesmos procedimentos da matriz utilizada na definição da fragilidade emergente para a Zona Agrícola.

$O$ resultado desse cruzamento foi a caracterização da fragilidade emergente ou vulnerabilidade da agricultura / produção de hortaliças nas unidades convencionais analisadas, cujos dados estão na tabela 9.

TABELA 9 - FRAGILIDADE EMERGENTE, FRAGILIDADE POTENCIAL E USO DO SOLO DAS ÁREAS DE HORTALIÇAS NAS UNIDADES DE PRODUÇÃO: VALORES ABSOLUTOS (HA) E RELATIVOS SEGUNDO AS CLASSES DE FRAGILIDADE

\begin{tabular}{|c|c|c|c|c|c|c|}
\hline \multirow{2}{*}{$\begin{array}{l}\text { CLASSES DE } \\
\text { FRAGILIDADE }\end{array}$} & \multicolumn{6}{|c|}{ ÁREA E \% } \\
\hline & $\begin{array}{c}\text { FRAGILIDADE } \\
\text { POTENCIAL (HA) }\end{array}$ & $\%$ & $\begin{array}{c}\text { USO DO SOLO } \\
\text { AGRICULTURA (HA) }\end{array}$ & $\%$ & $\begin{array}{c}\text { FRAGILIDADE } \\
\text { EMERGENTE }(\mathrm{HA})\end{array}$ & $\%$ \\
\hline 1- Muito Baixa & 21,8 & 12,7 & 0,5 & 0,3 & 0 & 0 \\
\hline 2 - Baixa & 28 & 16,3 & 81,6 & 47,6 & 31,1 & 18,1 \\
\hline 3 - Média & 38,7 & 22,6 & 74,6 & 43,5 & 52,5 & 30,6 \\
\hline 4 - Alta & 64,7 & 37,7 & 14,9 & 8,7 & 84,5 & 49,2 \\
\hline 5 - Muito Alta & 18,4 & 10,7 & 0 & 0 & 3,5 & 2,0 \\
\hline Total & 171,6 & 100 & 171,6 & 100 & 171,6 & 100 \\
\hline
\end{tabular}

FONTE: Almeida (2003)

Os dados mostram que, embora a capacidade de proteção do solo seja maior do que a predefinida inicialmente, a agricultura praticada na Zona Agrícola implica num elevado grau de vulnerabilidade do solo e, por decorrência, das águas. Isto se evidencia no fato de que $51,2 \%$ da área de hortaliças nas unidades de produção enquadram-se na classe de fragilidade emergente alta ou muito alta. Agregando-se a estes dados os $30,6 \%$ das áreas de hortaliças enquadradas como fragilidade emergente média, tem-se que $81,8 \%$ da área de hortaliças das unidades de produção estudadas sofre impactos ambientais consideráveis.

Este resultado é influenciado fortemente pela elevada fragilidade do meio físico onde se pratica a produção de hortaliças. O processo de intensificação produtiva e o aproveitamento de todas as áreas consideradas próprias para o cultivo pelos agricultores, tem levado a produção de hortaliças a áreas de elevada fragilidade. Neste caso, as práticas de conservação e o manejo, ainda que eventualmente favoráveis à conservação, tem seu efeito minimizado.

No caso inverso, ambientes potencialmente menos frágeis sofrem processos erosivos em decorrência da falta de práticas de conservação e o manejo intensivo do solo. Prevalece, portanto, a associação de solos frágeis e manejo intensivo com fortes impactos em termos de processos erosivos e elevado risco de contaminação dos recursos hídricos.

É preciso ainda abordar as especificidades da fragilidade ambiental decorrentes da presença do Aquífero Karst. Cerca de $40 \%$ dos produtores de hortaliças de Colombo, moradores sobretudo das comunidade Fervida, São João, Ribeirão das Onças e São Sebastião, têm suas áreas localizadas nas zonas de maior fragilidade do aquífero, onde a espessura da camada de solo que o separa da superfície é estreita, além de ocorrerem frequentes fraturas, tornando quase direto o contato entre a superfície e as águas subterrâneas. Estas áreas, pela baixa declividade, quando analisadas na Metodologia "A", têm minimizada a fragilidade a processos erosivos. Assim, ainda que neste trabalho não tenha sido possível mensurar os efetivos riscos de contaminação nestas áreas, é certo que a associação entre uma agricultura intensiva e áreas de maior fragilidade do Karst, significam uma situação potencialmente impactante, como mostrou Sanepar (2001b) e Fritzsons (1999). 


\section{CONCLUSÃO}

A Metodologia "A" tem seu grau de precisão associado à disponibilidade de mapas de uso do solo que permitam um detalhamento ao menos, quanto à presença de culturas de ciclo curto e longo, de tal forma a adequá-los aos padrões de enquadramento sugeridos por Ross (1994). O desenvolvimento de análises da fragilidade emergente em grandes extensões de área também tornam esse método bastante viável, na medida em que vantagens relacionadas à questões operacionais e de custo, compensam relativamente as limitações dos dados. Ainda assim, este método é limitado para identificar variações quanto ao grau de proteção do solo decorrentes das diferentes culturas implantadas e das diferentes formas de manejo em uso.

Deste ponto de vista a Metodologia "B", aqui sugerida, constitui um avanço, na medida em que reconhece e analisa com mais precisão as diferentes formas de uso agrícola do solo. Este procedimento é importante para que se rompa com uma visão equivocada que generaliza os impactos ambientais causados pela agricultura. Nesse sentido, torna-se também uma metodologia capaz de valorizar iniciativas de uso de técnicas agrícolas de caráter mais conservacionista.

\section{REFERÊNCIAS}

ALMEIDA, L. Mudança técnica na agricultura: perspectivas da transição agroambiental em Colombo - PR. Tese (Doutorado) - Universidade Federal do Paraná, Curitiba, 2003.

FLORIANI, N. Avaliação da fragilidade geossistêmica de uma microbacia sobre geologia kárstica: potencial e limitações. 133 f. Dissertação (Mestrado em Agronomia) - Setor de Ciências Agrárias, Universidade Federal do Paraná, Curitiba, 2003.

FRITZSONS, E. Avaliação do impacto da contaminação por nitrogênio na Bacia Hidrográfica kárstica de Fervida / Ribeirão das Onças - Colombo/PR. 164 f. Dissertação (Mestrado em Ciências Florestais) - Setor de Ciências Agrárias, Universidade Federal do Paraná, Curitiba, 1999.

IBGE. Folha topográfica $n^{\circ}$ 2842-2, Curitiba, 1968.

MENK, J. R. F.; MIRANDA, J. I. Levantamento pedológico e mapeamento do risco de erosão dos solos da Microbacia do Córrego Taquara Branca, Sumaré, SP. Jaguariúna: EMBRAPACNPMA, 1997. (EMBRAPA-CNPMA. Documentos, 9).

MERTEN, G.H. Impacto da mecanização do solo. In: PECHE FILHO, A. et al. (Ed.). Simpósio sobre impacto ambiental por uso agrícola do solo (SIMPAGRI). Campinas: Instituto Agronômico, 1994. p. 47-58. (Documentos IAC, 49).

MIRANDA, C. R. de. A tecnologia agropecuária e os produtores familiares de suínos do oeste catarinense. 218f. Dissertação ( Mestrado ) - Universidade Federal do Rio Grande do Sul, Porto Alegre, 1995.
OLIVEIRA, J. T. A. de. Lógicas produtivas e impactos ambientais: estudo comparativo de sistemas de produção. Campinas, 2000. 284 f. Tese (Doutorado) - Feagri, Unicamp.

ROSS, J. L. S. Análise empírica da fragilidade dos ambientes naturais e antropizados. In: Revista do Departamento de Geografia, São Paulo, n. 8, p. 63-74, 1994.

ROSS, J. L. S. Geomorfologia: ambiente e planejamento. 3 ed. São Paulo: Contexto, 1996.

SANEPAR. Relatório de Impacto Ambiental: exploração do aquífero Karst. Curitiba, 2001a.

Estudo de impacto ambiental da exploração do aquífero Karst das Sub-bacias de Colombo, Sede e Fervida. Município de Colombo-PR. Curitiba, 2001b. Tomo 1.

SANTOS, I. dos.; VITTE, A. C. Proposta de mapeamento da fragilidade ambiental na bacia hidrográfica do Rio Palmital, Região Metropolitana de Curitiba. In: FÓRUM GEO-BIOHIDROLOGIA: ESTUDOS EM VERTENTES E MICROBACIAS HIDROGRÁFICAS. 1., Anais... Curitiba, 1998.

SUDERHSA. Fotografias aéreas coloridas. Escala: 1:30.000. Curitiba, 2000.

- Sistema de informações geográficas para a gestão de recursos hídricos do alto Iguaçu. (Relatório Final e Fotografias Aéreas Digitalizadas.) Curitiba, 2002. 